\title{
The Design and Execution of Performance Management Systems at State Level: a Comparative Analysis of Italy and Malaysia
}

\author{
Carmine Bianchi \\ University of Palermo, Italy \\ John Antony Xavier \\ National University of Malaysia
}

\begin{abstract}
Performance management is maturing as an effective approach in public organizations around the world in improving public services. However, the existing models, based primarily on best practices of first-world nations, have limitations that must be addressed. One of which is the relative lack of attention to the context of performance management reform.

This international comparative case study analyses the experience of Italy and Malaysia in the design and execution of performance management systems at the national level. It seeks to contribute to the comparative literature on performance management across national jurisdictions. Italy and Malaysia also offer a contrasting study given their differing stage of economic development and extent of statism. Both these countries have a long history of reform to offer a good sample on the evolution of performance management at the national level of administration.

Based on selected interviews of stakeholders in the reform effort and literature review, this study investigates how performance management systems have changed over the past decades, the motivations behind their metamorphoses, their common elements across the two countries and what accounts for the respective progress in the execution of the two systems.

The study also inquires into the role that the institutional framework (formal, budget process, law mandating performance management, and planning and control systems) plays in bolting these systems on the fabric of public administration and in making the performance management systems robust.

The study presents policy recommendations and strategies on how governments can create more robust performance management systems for enhanced accountability and transparency in an age of resource constraint. These include the consideration of organizational setting (centralization or decentralization) for performance management, the development of financial and non-financial indicators, especially those that are outcomes-based, planning and control mechanisms, culture, the impact of performance management legislation, the role of administrative and political leadership, and the need for an informational infrastructure that supports performance management.
\end{abstract}

Keywords: performance management, national public-management reform, case study analysis, infrastructure, leadership, legislation, institutions, reform approach, reform motivation, public administration paradigm 


\section{Introduction}

Countries across the world have introduced periodically administrative reforms. These reforms have aimed to modernize their public administration so that their public sector can render services to citizens and the community better, at lower costs and at affordable prices. Many of these reforms are the inexorable march of public administrative modernization. Practices of more advanced countries tend to inform the content and process of reform in developing countries.

Performance management is one key area of public administrative reform. This is because performance management is an integral part of the public service delivery mechanism. It is a process by which a public organization can assess whether it is delivering the right services - according to its mission and objectives - in the right amount, at the right cost and at the right time. Performance measurement therefore requires an organization to set the objectives of its operations and develop meaningful performance indicators to measure performance (the quantity, quality, efficiency and outcomes of services provided). Against these indicators, targets of performance are set to meet the goals. And at the end of the process, performance management requires an assessment whether these performance targets have been achieved and what follow-up action is required based on this assessment (Bouckaert and Halligan, 2008).

Both Italy and Malaysia have been active in the area of performance management reform. Being at the opposite ends of the development spectrum, the two countries offer a perspective as to how performance management reforms in these countries have progressed and what have been critical to their respective progress.

There are limitations to a comparative study given differing cultures and values of the public sector of the two countries. So the intention of this study is not to offer clear-cut conclusions. Neither is it to identify objectively the 'best' model of performance management. Rather, this study seeks to ascertain commonalities in the design and execution of performance management systems (PMS) across jurisdictions and to determine the critical success factors required to sustain performance management in the public sector. 


\section{Performance Management in Italy}

This section traces the evolution of the PMS. It highlights the shifting approaches to reform as well as identify the critical success factors that account for the progress of PMS reform.

In the last three decades, Italy has produced a significant effort in setting the rules on PMS in the public sector. Since the beginning of the ' $80 \mathrm{~s}$, both increasing financial problems in the Italian public sector and a rising dynamic complexity have been a major cause of an intensive legislation leading to administrative reforms. The spirit of such an effort has been at least oriented to six main goals, i.e.: 1) to set forth the compulsory nature of planning and control $(\mathrm{P} \& \mathrm{C})$ as a process aimed to monitor the efficiency and effectiveness through which public resources are exploited; 2) to empower specific organizational units - either inside a public sector institution, or outside of it - to play an active role in performing the $\mathrm{P} \& \mathrm{C}$ function; 3) to evaluate the performance of employees and groups, to make them accountable to expected service delivery standards; 4) to foster coordination between the political and managerial level, as well as across different sectors in both a public sector institution and through different institutions; 5) to ensure public sector transparency; 6) to promote the development of a culture and profession of performance management in public sector organizations.

It is possible to distinguish five main and interconnected steps through which the Italian State has been setting rules on the design and use of $\mathrm{P} \& \mathrm{C}$ to foster public sector performance management. Though in each of the stages the focus of legislation has been somewhat different from others, each subsequent stage has embodied the previous ones. Such steps can be framed as follows:

a) Monitoring the financial equilibrium of municipalities and other local authorities;

b) Financial control, operated on behalf of the political level, on the efficiency and effectiveness in resource allocation by managers in the State and local public sector organizations;

c) Financial budgeting and planning;

d) Integrating financial budgeting with strategic planning;

e) Embodying budgeting and strategic planning into a broader performance management cycle. 


\section{Monitoring financial equilibrium at municipal level}

The first step towards public sector performance management undertaken by the Italian legislation dates back to 1986 , when the legislative decree No. 318 provided specific precautionary measures to counteract the risk of emerging financial deficits in municipal administrations, due to unrecorded liabilities. The Act No. 142/1990 (art. 51, 55, and 57) set forth specific rules regarding the reorganization of municipal offices and service delivery. Specifically, it stated the principle of separation of roles between political leaders and administrators. This Act also prescribed specific rules for local public sector institutions in terms of financial planning and accounting. Two fundamental principles behind the pursuit of financial equilibrium and transparency were set, i.e.: 1) expenditures can be authorized only if enough revenues are available to afford them, and 2) no accounting balance between specific collections and disbursements must be operated. Furthermore, this Act attributed to the accounting auditors the role to carry out internal control.

\section{Financial control on the efficiency and effectiveness in resource allocation}

A significant move towards a second evolutionary stage can be referred to the legislative decree No. 29/1993. On the one side such decree reinforced the principle of separation of roles between political leaders and administrators; on the other side, it focused its own attention on monitoring managerial results, as a prerequisite for the pursuit of financial equilibrium. Such effort was still predominantly centered on the financial side of performance management.

In particular, this decree prescribed that, in each Ministry, at the beginning of every year a report on the results achieved in the previous year should have been submitted by managers to their own general manager, and by the general manager to the Minister.

Also, it was prescribed that, in each Ministry, specific "Internal Control" (or "Performance Evaluation") units would have been established. These units were set in an autonomous position - in respect to each department - to support elected officials to assess managerial performance ${ }^{\mathrm{i}}$.

Although the task of the "Internal Control" units was still mainly bounded to a financial domain and to only a support to the elected officials in evaluating managers in the implementation of political goals, the decree No. 29/1993 introduced a major innovation towards the adoption of PMS in the public sector. In fact, it outlined how the function of the control unit is different from that of an auditing unit. 
The autonomy of planning, control, and results evaluation from internal auditing was therefore stated for the first time by the Italian law.

\section{Financial budgeting/planning}

The pursuit of such effort towards the identification of an autonomous role of $\mathrm{P} \& \mathrm{C}$ as a professional function aimed to support management was further developed in a third evolutionary stage. This stage tried to combine the focus on the pursuit of financial equilibrium with the need to carry on P\&C over the financial results.

Regarding this, an important effort can be referred to the public sector accounting reform. Since the Act No. 468 was issued in 1978, the Italian legislator has gradually supported the introduction in the national budgeting system of an accrual and cash-based mixed approach (Caperchione \& Mussari, 2002, p. 308; Mussari R., 2005). Also, harmonizing accounting systems of the Italian public sector institutions at different levels (State, Region, Municipality) by adopting homogenous charts of accounts, has been considered as an important step to pursue financial equilibrium in the extended Italian system, to comply with the stability pact adopted in 1997 by the member states of the European Union. Such effort has been pursued by several acts, starting from the law No. 196/2009 (art. 2), to the legislative decree No. 91/2011 (art. 4).

The accounting system plays a central role in the Italian State planning process: in fact, it drives the drawing up of financial statements to report both planned and actual results on expenditures and revenues. Concerning this, the legal framework primarily addresses accounting and balance sheet activities, but constitutes an important basis in terms of planning.

The Act No. 39/2011 (art. 2) prescribes the structure of the financial planning cycle for the Italian

State. ${ }^{\text {ii }}$ The current system requires the government to submit an annual budget proposal, along with a three-year financial plan, to the legislature for each forthcoming fiscal year. The budget proposal is the result of a synthesis of the budget proposals submitted to the prime minister and the Ministry of Economy and Finance (MEF) by the ministers. While the budget proposals can be characterized as more of a financial exercise than an evaluation of goals and outcomes, the three-year financial plan requires a level of strategic thinking beyond the forthcoming fiscal year. 
The structure of the proposed budget submitted to the legislature, however, does not facilitate performance management. For example, the proposed budget contains, for each ministry, the financial resources allocated to each department. It then disaggregates departmental budgets by the specific units of service delivery. This system hinders decision-making in two ways. First, it makes it difficult to track budget-to-actual variances for the total cost of service delivery. Second, it does not support planning and performance management where performance measures are properly aligned with resource consumption.

\section{Integrating financial budgeting with strategic planning}

A fourth state in the metamorphosis of the Italian legal framework into formal performance management systems can be evinced in the attempt to integrate financial budgeting into a wider strategic planning perspective, by using an organizational and managerial approach.

This stage can be related to the introduction of "Internal Control" units as facilitators of the P\&C process.

As previously mentioned, such units were introduced by the legislative decree No. 29, in 1993. However, a major change towards the goal of establishing formal performance management systems in the Italian public sector has been made by the legislative decree No. 286/1999.

Such decree prescribed that, in order to monitor and improve performance, Italian public sector organizations adopted proper 'internal control' tools, aimed to:

1. Guarantee a legal, regular and correct fulfillment of administration (internal auditing);

2. Assess the effectiveness, efficiency and the economic equilibrium in the fulfillment of administrative tasks (management control);

3. Evaluate managers' performance; and

4. Assess the level and quality of implementation of public policies (strategic control).

The perspective adopted by the Italian legislator to cluster different kinds of controls was the positioning of the control unit in the organization being "controlled". So, "internal" controls were distinguished from "external" controls, since the latter are performed by third institutions (e.g. a court of auditors), usually with the primary purpose to verify whether administration is carried out in 
compliance to formal rules. Though such a perspective is a major step ahead in identifying a broad set of functions performed by staff units inside a public sector organization, it does not focus yet the true nature of performance management. In fact, while strategic and management control, as well as performance evaluation are clearly identified in this clustering effort, internal auditing is also considered as another relevant activity for performance improvement, though it does not primarily relate to the critical issues that a controller typically faces.

Related to management control, the decree No. 286/99 prescribed that specific staff units would have carried out such activity. The law identified a set of core functions of management control. Concerning this, the 'design' role of control was distinguished from the activity of performing the control itself. An organizational analysis to implement control was claimed. The design of the organization procedures related to budgeting, and the identification of administrative products were mentioned. Other core tasks were referred to: the measurement of performance standards, the selection of performance indicators and reporting.

The same decree outlined strategic control as an activity carried out by a unit responding to the Minister. It prescribed that strategic control should focus, at both planning and post-action level, on how managers implement public policies, missions, and strategic objectives. The identification of obstacles, responsibilities and solutions to the implementation of public policies were mentioned as core strategic control functions. Three main strategic control activities were distinguished, i.e.: 1) evaluating the performance of first line managers; 2) supporting them in identifying problems and solutions; 3 ) supporting strategic planning and linking it to implementation.

To implement strategic and management control (and link them each other), the decree prescribed each Minister should annually issue a directive, i.e. a main strategic planning document embodying the intersectoral goals outlined by the prime minister, and the corresponding strategic objectives for each sector of public administration.

Provided that planning is tightly ruled by the legislation about the three and one year "accountingdriven" financial budgeting, it is possible to perceive the dual nature of such process in the Italian public sector. One part of the system is the process of preparing the proposed budget and three-year financial plan. The other part of the system, known as the directive, is the process through which the prime minister and each of the ministries issue a political document formalizing the next fiscal year's strategic goals. These parts together are derived from the "Economic and Financial" document (DEF), 
which depicts the strengths/weaknesses, opportunities/threats associated to the planning process and referred to at least a three-year time horizon (Ministry of Economy and Finance, 2013).

Each ministerial directive also contains a series of action plans, i.e. the documents through which the resources allocated to the various departments are specified and associated with activities to achieve their respective goals and objectives. An action plan formalizes the performance measures and targets agreed on between the minister and the department heads, as well as the timeframe for which performance will be assessed.

While action plans and corresponding performance reports are supposed to define the financial resources allocated for each action and objective, in relation to each department, this does not happen in practice. There are several reasons for this disconnect between departmental budgets and action plans. One is associated with weak financial management systems, while another can be attributed to the weak performance management culture iii.

The law also requires an association between performance management systems and annual personnel evaluations. This relationship helps determine the financial bonuses that are given to managers within each ministry. This last domain of performance management has been focused by the legislative decree No. 150/2009.

This decree marks the fifth stage in the metamorphosis of formal performance management systems as ruled by the Italian law.

\section{Incorporating budgeting and strategic planning into a broader performance management cycle}

The legislative decree No. 150/2009 has injected a massive trend of new reform (OECD, 2010, p. 1929). The main problems confronted by this reform can be summarized according to the following principles:

- Planning, performance, and evaluation are a continuous process rather than a succession of fragmented and isolated events. Therefore, a performance management cycle should be consistently managed.

- Strategic planning and operational budgeting must be linked to financial planning and balance sheets accounting, in order to make the dual budgeting process internally consistent. 
- Performance must be measured and evaluated at two stages: organizational and individual. The former concerns the implementation of outcome measures on a departmental level. The latter refers to the contribution of individual employees.

- Performance management implies the proper use of objectives and performance indicators. Monitoring performance and implementing periodic corrective action also are required.

- A performance plan must be outlined every year, involving elected officials and administrators.

- A common methodology must be adopted to design and implement performance management systems by different Italian public sector institutions.

- Independent program evaluations are required by oversight units, outside of political and managerial control.

- The public sector must ensure transparency towards citizens and the community: to this end, usersatisfaction surveys can become a powerful performance management tool, to connect front offices with back offices in the public sector (Bianchi, 2010 and 2012).

Regarding the first six principles, the indisputable merit of such law is to build and systematize on the legal prescriptions and implementation experiences developed in the Italian public sector in the previous two decades, on performance management.

However, if observed on a different perspective, such effort could be considered as unfocused or redundant - in respect to the role that legal frameworks are expected to play in this context. For instance, the law provides details on the stages of the performance cycle (art. 4): to this end, the legislator seems to fully borrow the conceptual framework from the scientific literature (Flamholtz, 1996, p. 18). Also, the law remarks the characteristics that objectives and corresponding performance measures should have (art. 5), according to S.M.A.R.T. criteria (Doran, 1981).

It can be disputed whether it is the role of law to 'teach' or prescribe how to design and implement PMS, or whether it should rather set the context where practitioners - and primarily, skilled controllers, duly endorsed by the political leaders and administrators - can be enabled to operate. Two possible explanations may provide insights in this regard, i.e.:

1) The legislator adopts a mechanistic approach to frame the controller's profession. This implies that the context $\mathrm{P} \& \mathrm{C}$ systems deal with are expected to be structured and predictable, so that performance management can be bounded to the implementation of detailed and bureaucratic 
procedures ${ }^{\text {iv }}$. This takes out of consideration both the behavioral implications associated to the adoption of formal performance measurement systems and the need to take a contingent approach to foster coordination, due to the dynamic complexity organizations face. A focus on the tools (e.g.: information systems, accounting, or statistical computations) runs the risk of misplacing the attention from the design and the use of consistent P\&C systems from inside each public sector organization. The perils of such approach have been demonstrated since a long time ago (Hofstede, 1978; Merchant, 1982).

2) A tight and rigid culture, which is driven by a spirit of compliance - rather than of continuous improvement and strategic organizational learning - may threaten the search and adoption of innovative methods. This culture is inclined to bureaucratically implement only the explicit legal frameworks' prescriptions.

Perhaps the major structural innovation operated by the Decree No. 150 can be related to the discipline of performance evaluation. Here, the independence of evaluators is emphasized. The law sets for each Italian public sector institution, two new kinds of units, i.e.: 1) the "Committee for the evaluation, transparency, and integrity of public administrations" (OECD Public Governance Reviews, 2013), and the 2) "Independent Unit for Performance Evaluation" (Bigoni \& Deidda Gagliardo, 2013, p. 408).

The "Committee" is a central administration unit which carries out three main roles: 1) to support the political and managerial levels in adopting performance management systems; 2) to support the "Independent Unit for Performance Evaluation" in managing the critical issues detected in carrying on its function; 3) to ensure public administration transparency and undertaking anti-corruption practices $\mathrm{v}$.

The "Independent Units for Performance Evaluation" are mainly in charge of: 1) monitoring the managerial performance evaluation system; 2) validating performance reports; and 3) checking the fairness of performance measurement. Such units are located - in a position of autonomy - in each of the ministries or agencies of a public sector institution.

A formal performance evaluation system is adopted by ministries, usually including a major consideration of the technical expertise of the manager to handle the activities embodied in the performance plan and for organizational leadership portrayed by the manager in the observed time span. The evaluation of each manager is performed by the incumbent of the next-higher hierarchical 
position; however, its ultimate validation depends on the decision of the "Independent Unit for Performance Evaluation".

The Decree 150/2009 has significantly amended the previous legislation. In fact, although it sets a specific unit for performance evaluation, it does not establish any corresponding staff units to support the political and administrative levels to carry on the other performance cycle activities. It just prescribes that each minister, with the collaboration of department heads, must annually issue a directive with a three-year performance plan. Also, they must annually monitor the emerging results from the implementation of performance plans, based on which they will submit performance reports.

Although the law does not prescribe anymore that a strategic control staff unit must be set up in each ministry cabinet, the need to outline robust directives and performance plans requires that a group of strategic P\&C analysts facilitates the planning process. Such analysts should play an active role inside cabinets in fostering a strategic dialogue with administrative levels in identifying - with the collaboration of department management control units - the operational objectives, as well as performance standards and measures on which administrators will be made accountable, to attain the strategic goals. Unfortunately, the P\&C staffs often do not have enough personnel and possess limited skills regarding performance management.

An outcome of the weak performance management culture and the limited technical support can be found in the vagueness that often characterizes the strategic goals and operational objectives included in the directives of the various ministries. It is not uncommon for operational objectives to be defined merely as activity descriptions rather than measurable objectives and outcomes.

While these and other challenges still place the Italian State in the early stages of the maturity process of performance management, the legal framework seems to push the public sector down the road toward the adoption of formal performance management systems.

One may argue that laws and rules, together with training, have produced a few (maybe still marginal or even erratic) improvements that have been cyclically creating hope, but also sudden discouragement, about possible future developments in the Italian State.

\section{Performance Management in Malaysia}


Administrative reform in the Malaysian public service has been largely politically inspired and at times politically-driven. Accordingly, performance management reform has always been high on the government agenda. Given the priority accorded to performance management, Malaysia's experience developing PMS has gained the distinction of being made an inspiration among developing countries especially as they pursue public management reform.

\section{Evolution of Performance Management}

The first seeds of performance management were planted in 1968 with the introduction of the Planning and Programming Budgeting System (PPBS). ${ }^{\mathrm{vi}}$ The PPBS sought to allocate budgets across government programs on the basis of planned levels of service delivery. This performance-based system of resource allocation was to transform the PMS from an input-based to an output-based system.

However, its lackluster performance - the lack of performance targeting, measurement and the nonexistence of performance evaluation - and as a performance management tool caused the Ministry of Finance to make radical modifications to PPBS in 1988 (Xavier 1996a). These modifications entitled the Modified Budgeting System (MBS) - sought to resuscitate performance measurement annually and the long-term program evaluation to revive the principle of budgeting based on planned performance. ${ }^{\text {vii }}$ Performance agreements became the vehicle to do so. These agreements were commitments by ministry heads to the Ministry of Finance (MoF) to a set of performance targets for each activity in their budget structure for the proposed level of funding. They aimed to explicitly relate outputs with the cost of producing them (Xavier, 1996b). ${ }^{\text {vii }}$

To fortify performance measurement and introduce output costing the Malaysian Administrative Modernization and Management Planning Unit of the Prime Minister's Department (MAMPU) introduced the Micro-Accounting System (MAS) in 1987 and further revamped it in $1992 .^{\text {ix }}$ By enabling agencies to identify the cost of their outputs, the MAS allowed budgets to be prepared by compiling the costs of the planned levels of outputs.

Closely on the heels of the MBS, the Government introduced the Productivity Improvement initiative 1991. ${ }^{\mathrm{x}}$ This initiative was to help identify performance indicators that would be useful under MBS. Ministries and agencies were required to measure productivity in terms of time, cost and manpower. And these measurements were to be compared across time or to standards to determine the relative level of efficiency of the agencies. 
As if these initiatives were not enough to instill a culture of performance within the public service, the Government introduced the Total Quality Management or TQM in 1992. ${ }^{\text {xi }}$ TQM emphasized the importance of results from government operations, customer orientation in public service delivery (TQM required an agency to identify clients and document clients' needs), and the importance of quality control, both at the level of process and final output. Again, this new initiative was to build on past schemes of performance management. It was to keep the issue of performance management alive in the civil service.

To further ensure quality in service delivery, ministries were required to draw up their clients' charter beginning 1993. ${ }^{\text {xii }}$ The Clients' Charter took the TQM a notch higher. It not only emphasized customer orientation in the public service. It also committed the public service to a set of publicly documented commitments on the quality and timeliness of the services provided. Clients then had an opportunity to know at what level of quality a particular public service would be rendered to them. They would then be able to evaluate the performance of a public agency and compare the standards of performance with those of other comparable agencies locally and abroad. They would then have a right to complain were these service standards not met.

To further build on the TQM emphasis on process quality control, government agencies actively pursued the MS ISO 9001 certification (and other subsequent versions) as of $1996 .^{\text {xiii }}$ The ISO was to document the processes involved in producing a particular service. Duplication or unnecessary processes were to be eliminated. A streamlined process of service delivery should result in good process control. That in turn should ensure the quality of the final product.

Benchmarking joined the performance management reform list in $1999 .{ }^{\text {xiv }}$ Benchmarking sought to strengthen the public service culture of performance by requiring agencies to emulate best practices locally and abroad - in the related areas of service delivery. Benchmarking was to motivate agencies to set standards of performance against the best in the world.

The 2005 Key Performance Indicators (KPIs) initiative by MAMPU further invigorated the PMS. ${ }^{\mathrm{xv}}$ KPIs were to be developed by agencies to measure the quality of service delivery. This KPI initiative was strengthened and supplemented by the 2007 MoF Srategic KPI initiative. This initiative required agencies to identify strategic result areas and strategic KPIs to measure the results of operations in these strategic areas. Agencies were also to identify KPIs and targets to measure outcomes or impact. The achievement of these targets is a form of accountability for the public funds expended on a 
particular program. Information from performance measurement and monitoring could then be used to further improve performance.

The 2006 saw the auditor-general evaluating the financial management performance of ministries and rating their performance annually on the basis of stars. A one-star rating would denote a deplorable state of financial management while a four-star rating would mean that the financial management of the ministry is excellent. The criteria for the financial management system rating comprise the core areas in financial management. These include budget planning and execution, revenue collection, asset management, procurement, payments and financial record keeping. The star rating enables ministries to assess where they stand in relation of others in financial management. Such a relative standing helped apply pressure on ministries to not only buck up, should they have not scored well, but also to maintain their rating should they have performed exceptionally well.

In 2007, MAMPU also came up with its star rating system to score the overall performance of a ministry's management. MAMPU's five-star rating assessed a ministry's performance from poor warranting only one star - to excellent and deserving of five stars. The criteria of assessment include strategic planning and evaluation of execution, human resource management, financial management, policy and program formulation, execution and evaluation and complaints management.

The rating system of the auditor-general and MAMPU has put pressure upon agencies to continually seek out improvements in public and financial management so that they can secure the most prestigious rating (Xavier, 2009).

A performance scorecard for ministry heads was introduced in 2007 to further augment the PMS. This initiative combines the individual performance of the ministry head and that of this or her organization to determine the ministry head's performance

Recognizing that the heads of department would need the support of their deputies in accomplishing their KPI targets, the government extended the KPI project to the deputy ministry heads as well. The KPI targets of the ministry heads are cascaded to the performance scorecard of the deputies (Xavier, 2009).

In 2010, the government introduced the Government Transformation Program (GTP). Unlike the previous reforms that applied service-wide, the GTP takes on a focused approach to service delivery. Ministers who are responsible for the seven national key result areas are given a performance 
scorecard with performance targets. The rest of the cabinet ministers too are given a performance scorecard for their respective ministries. All ministers are accountable to the prime minister for the achievement of their performance targets. The agency made responsible was the Performance Management and Delivery Unit at the Prime Minister's Department (PEMANDU).

The new outcomes-based budgeting system (OBB) implemented on a pilot basis from 2012 seeks to get agencies to measure not just outputs but also outcomes and impact of public expenditure. OBB also requires agencies to evaluate the success of the programs against their goals, thereby resuscitating the initiative of previous performance management reforms respecting program evaluation.

Accrual accounting is the latest accounting initiative to help capture the full costs of service delivery. That way a better understanding can be obtained on the efficiency and effectiveness of public expenditure.

Table 1 summarizes these major milestones in the Malaysian public service performance management efforts.

Table 1: Key performance-based reform efforts of the public service

\begin{tabular}{|l|c|}
\hline \multicolumn{1}{|c|}{ Reform } & Date \\
\hline 1. Program and Performance Budgeting System (PPBS) & 1968 \\
\hline 2. Micro-Accounting System (MAS) & 1987,1992 \\
\hline 3. Modified Budgeting System (MBS) & 1990 \\
\hline 4. Productivity Improvement & 1991 \\
\hline 5. Total Quality Management & 1992 \\
\hline 6. Clients' Charter & 1996 \\
\hline 7. ISO & 1999 \\
\hline 8. Benchmarking & 2005 \\
\hline 9. Key Performance Indicators (KPIs) & \\
\hline
\end{tabular}




\begin{tabular}{|l|c|}
\hline 10. Treasury Strategic results areas and strategic KPIs & 2007 \\
\hline 11. Auditor-General's Star Rating on Financial Management & 2007 \\
\hline 12. MAMPU's Star Rating System on Public Management & 2007 \\
\hline 13. Permanent Secretary Performance Scorecard & 2008 \\
\hline 14. Government Transformation Program & 2010 \\
\hline 15. Outcomes-based approach to Budgeting (OBB) & 2012 \\
\hline 16. Accrual Accounting & 2014 \\
\hline
\end{tabular}

\section{An analysis}

This section offers an analysis of the motivation and approach to the PMS reforms over the past 50 years.

\section{Motivation for reform}

As with the others, the PMS reforms have been largely at the direction of the political leadership. Prime ministers have always made administrative reform a top priority. They have relied on the public service to provide quality services at affordable prices so that the expectations of an increasingly consumerist public can be met and with that their political office maintained. The latest PMS approach - the GTP - specifically addresses the concerns of the public. It was crafted after the ruling government fared relatively badly at the elections (Iyer, 2011).

\section{$\underline{P M S}$ and public administration paradigm}

PMS reform has broadly reflected the changing paradigm of public administration. The introduction of the earlier set of reforms in the $70 \mathrm{~s}$ through $90 \mathrm{~s}$ mirrored the shift from progressive public administration, with its focus on inputs and procedural compliance, to outputs and efficiency. The latter move was in line with the dictates of the New Public Management paradigm (NPM). More recent reforms, while still true to NPM marked a shift to the Responsive Governance or the Public Value paradigm (see O'Flynn, 2007; World Bank, 2012). The GTP especially, with its focus on 
crime, corruption, poverty, urban transportation, cost of living, and rural infrastructure development, was a clear response to the needs and concerns of the public.

PMS reforms have been buttressed by the relevant institutions. These include the budget process, central government directives and dedicated reform institutions such as the MAMPU and PEMANDU.

\section{Institutional Framework}

PPBS, MBS and OBB were systems within the budget process. The Financial Procedure Act, 1957 and its subsidiary legislation - the Treasury Instructions - allowed the MoF to issue budget circulars that mandated how performance management was to be conducted as part of the budget process. Ministries were accountable to the MoF for their performance through performance agreements. The latter formed the budget documentation for budget proposal and approval by Parliament.

Just as the other administrative reforms, the relevant central agencies directed and coordinated the PMS reforms. PMS design and implementation was more top-down based on central fiat. The MoF designed and implemented the budget-related PMS systems. MAMPU, Public Service Department, PEMANDU and Audit Office pioneered PMS systems that were aimed at modernizing public administration. The latter departments were under the Prime Minister's Department. The high office of the Prime Minister and that of the MoF provided heft to the reform initiatives (Siddique, 2010).

These institutions offered the P\&C systems to make the PMS robust. KPIs and target-setting were jointly done between the central authorities and the ministries. Periodic monitoring, year-end evaluation and feedback to central authorities, especially to the Prime Minister, and ministers kept PMS robust.

\section{Approach to reform}

Local and overseas best practices informed the PMS reforms. The US and Australia inspired developments in performance-based budgeting. The GTP mirrors a similar system under Tony Blair's government (see Barber, 2009). The UK inspired the Client's Charter initiative while private sector practices motivated the quality-based performance management such as TQM and ISO.

The PMS initiatives did much to introduce a culture of high performance in the public service. What comes out loud and clear is the government's persistence and tenacity to reform. Although one cannot categorically say that a particular PMS effort improved public services, in combination the PMS reforms have contributed to improved public services. 
This improved state of public services has been largely because each new initiative snow-balled all upon another to create a critical mass or synergy to permanently embed performance management in the public service. This emphasis of gradually building on past practices has resulted in a culture of performance evolving within the public service - a culture that values a performance-based rather than an input-focused management.

This snow-balling of PMS reform initiatives has also been possible because successive PMS reforms incorporated elements of previous initiatives. For example, the ministry-head's performance scorecard included the star ratings of MAMPU and the Auditor-General's Office, the strategic KPIs of the MoF initiative and the KPIs of the Client's Charter (MAMPU, 2010).

Increasingly, the focus of the PMS effort has been to incorporate outcome-based KPIs that measure the efficiency of government operations, service quality and the achievement of departmental goals. The OBB seeks to explicitly incorporate outcome measures in the budget to assess what goals have been achieved for the money spent. Challenging performance targets for the KPIs have been introduced. For example, the KPIs for ministry heads have a conventional target and two stretch targets.

Apart from the performance scorecard for ministry heads, previous PMS reforms made little attempt to explicitly link organizational performance goals with individual performance objectives. While performance management initiatives have been careful in ensuring that performance is measured against organizational goals, there is no explicit link with the larger public service or national mission and goals. Perhaps, the presumption is that public agency goals must necessarily be aligned to the larger public service or national agenda.

The recent GTP effort acknowledges that central bureaucratic fiat for reform will not do. That had been the chief catalyst for almost of the PMS reforms. Under the GTP, operating ministries and agencies are being consulted as equal partners in improving services in the national key result areas. The GTP also did the hitherto unheard job of soliciting public participation to its agenda. Such consultation on an equal footing among all parties will engender commitment especially of the spending ministries. Such commitment will ensure that the reform effort does not proceed on the steam of the central authority spearheading the reform alone but on the combined strength of all the parties concerned. 


\section{Summary and Findings}

Despite their differing stages in economic development, both Italy and Malaysia show commonalities in their reform approach, experience and the critical success factors in PMS reform. This section highlights a number of interesting findings that might enable a discussion on the policy recommendations and organizational strategies to sustain public sector reforms towards the adoption of more robust PMS for higher levels of accountability and transparency.

To conduct such comparative analysis we have used the framework adopted in Bianchi \& Rivenbark (2012, p. 522-525). This framework identifies cultural and organizational structures, legislation, leadership, informational infrastructures, and performance indicators as key components for the success of PMS reforms.

\section{Reform Motivation and Progress}

In both the two nations we observe that reform implementation was a result of a necessity. Such a necessity for reform was born out of a fiscal crisis or a political crisis consequent to an erosion of public trust in government. Accordingly, the early efforts of PMS reform focused on improving the efficiency and effectiveness of resource allocation in both the countries.

While that concern remained the recurring theme in subsequent reforms, the necessity to modernize public administration too has underpinned efforts at PMS reform. Such modernization was to demonstrate to an increasingly skeptical public that the government was indeed serious in improving public services.

The political motivation to reform is also evident in both the countries. Indeed, in most instances, the political level has been instrumental in driving PMS reforms.

Reforms were not conducted in isolation of previous ones. We see in both countries subsequent reforms incorporating the components of the older set of reforms. In this way, reforms were incremental and consistent with past efforts. Building on the older reforms lent further legitimacy to the new initiatives while maintaining the momentum of PMS reform effort.

\section{Culture and Organizational Structures}

The second lesson from the comparative study is that the design and implementation of PMS in national governments must recognize the difficulty of transforming culture and organizational 
structures. Through a constant stream of PMS reforms both the governments hoped to cultivate a culture of performance in their respective jurisdictions.

Our study supports Pollitt's (2006) contention that centralized governments are more adept at performance management than decentralized governments. In both the Italian and Malaysian systems the planning process is centered at the prime minister level. That enabled more effective reform policies and their co-ordination and implementation across ministries. However, in Italy, public officials' sensitivity to the demands of their own constituents has at times hindered the prime minister's ability to implement policies across ministries and has compromised performance issues of efficiency and effectiveness of public expenditure (Ongaro \& Valotti, 2008).

On a more micro-perspective, another relevant organizational issue can be related to the formal identification of specific staff units supporting the political and administrative levels in carrying out the performance management cycle. Whether explicit formal units supporting the P\&C process are beneficial or not to the performance of PMS cannot be demonstrated. However, both the countries have set up independent evaluation units to help political and administrative masters to assess performance objectively, draw ministries' attention to critical issues in service delivery and to pursue a more outcome-oriented approach in performance management.

Additionally, internal audit units in the ministries of both the governments have also sought to make $\mathrm{P} \& \mathrm{C}$ controls more robust to ensure efficiency and effectiveness of public expenditure.

\section{Legislation}

The third lesson that can be drawn from our comparative research is that an elaborate structure of legislation, which prescribes the adoption of a formal PMS, does not guarantee success. The slow progress to an outcome-based performance management approach and the lack of a clear nexus between public expenditure and outcomes is testimony to the impotency of legislation to bring about such changes.

Notwithstanding, the laws and directives fostered a sense of urgency towards the implementation of innovative methods of performance management. In both Italy and Malaysia there was a gradual evolution of their respective legislative frameworks from an input to output and finally towards outcome measurement. 
Without a major improvement in professional skills, an organizational structure that is geared to measuring performance and following up on the results, and a shift from compliance to continuous learning, public administrations will not be able to pursue an outcomes-based approach to performance management with vigor.

\section{Political and Administrative Leadership}

A fourth lesson from our comparative study is the need for political and administrative leadership. Notwithstanding legislation on PMS, political leadership plays a key role in setting the agenda for performance management reform. While the political leadership sets the tone and tempo of reform, administrators play the key role in managing the planning process, creating the informational infrastructure and coordination mechanisms, selecting the performance measures, and evaluating the results.

The outcome from this finding is that administrators must work with their political masters to bring about improvements in public services. Governments must identify and cultivate champions of performance management. This implies a need for leadership from elected officials, agency directors, and $\mathrm{P} \& \mathrm{C}$ staff in creating meaningful performance measures and promoting program evaluation (Kelly \& Rivenbark, 2011).

\section{Informational infrastructure}

A fifth lesson is the need for an informational infrastructure to support performance management. Without a system-wide informational structure each agency or department might develop its own fraction of performance management, without considering the interdependencies that not only at a macro (or political) level, but also at a micro level are relevant to assess performance outcomes. Also this principle is crucial to link the financial to the non-financial side of performance management (dual planning system). This effort has been pursued by both Italy and Malaysia.

\section{Performance measures}

The sixth and equally important, lesson drawn from the comparative study is the need to aggressively adopt relevant and meaningful performance indicators. This selection is important if performance indicators are to help decision-makers assess the progress made by the organization towards the achievement of the pursued goals. Accordingly, the need to extend the domain of adopted performance 
measures from input and process to output and outcome indicators is a key factor that may significantly contribute to an effective design and implementation of PMS.

Also the possibility of extending the identification of KPIs to national key results areas or strategic reform areas (SRAs) related to the political level, is a key for the evaluation of public policies and to foster a strategic dialogue and learning between elected officials and managers. Such experience has been successfully implemented in Malaysia and should be an important benchmark for the Italian PMS.

\section{Conclusion}

The paper highlighted the developments in PMS across two jurisdictions of differing levels of development. Yet, the problems in implementing the PMS are similar in both. The PMS in both jurisdictions has not matured to measure outcomes and impact. There is little explicit link between performance and resources expended and performance evaluation over the longer term is limited. The cascade of organizational performance targets to individual performance targets remains elusive in both the jurisdictions. Performance measurement will be even more beneficial if the measurement results are fed into the strategic planning or budget cycle.

Despite these deficits in implementation, PMS development exhibits similarities in Italy and Malaysia. Early reforms were anchored in financial and budgetary management. These were intended to ensure greater efficiency and effectiveness in public expenditure. Additionally, the reforms sought to introduce greater accountability and transparency in public service delivery. The reforms also sought to stem the erosion of public trust in government. The PMS reforms drew their strength from the elaborate legislative structure as they did from the political leadership that pressed home the performance agenda to improve public services.

The comparative study has revealed that the bureaucratic culture can be gradually reshaped to become more performance oriented if the public sector is given constant injections of performance management reform. Structures, such as dedicated performance management or evaluation units, must be in place at the center of government as well as at the ministries and agencies if PMS is to take root in the public sector. 
Legislation is important in the execution of PMS reforms. It lends legitimacy and an aura of formality to the reforms. However, legislation alone will not take the reform effort to a higher plane. To enhance performance management, and service delivery, elected officials and department heads should take on the leadership to see the reforms through. That means that performance management must not be played at the level of inputs and outputs. The PMS cycle must be completed with a good dose of outcomes measurement to assess goals achievement and effectiveness in public expenditure.

\section{Bibliography}

Barber M. (2009). Instruction to deliver: fighting to transform Britain's public services. London: Mathuen Publishing Ltd.

Bianchi C (2010) Improving performance and fostering accountability in the public sector through system dynamics modeling: from an 'external' to an 'internal' perspective. System Research \& Behavioural Science, 27(4), p. 361-384.

Bianchi C. 2012. Enhancing Performance Management and Sustainable Organizational Growth through System Dynamics Modeling, in: Groesser, S. N. \& Zeier, R. (Eds.), Systemic Management for Intelligent Organizations: Concepts, Model-Based Approaches, and Applications, Heidelberg, Springer.

Bianchi, C. \& Rivenbark W. (2012) A Comparative Analysis of Performance Management Systems: The Cases of Sicily and North Carolina. 2012. Public Performance \& Management Review, 35, 3, p. 509-526.

Bigoni M. \& Deidda Gagliardo E. (2013). Brunetta's reform swan song? An assessment of its success in local governments through the analysis of its tools, European Scientific Journal, 9, 29, p. 403-428.

Bouckaert, G., \& Halligan J. (2008). Managing performance. London: Taylor \& Francis Group.

Caperchione \& Mussari (2002). Caperchione E. - Mussari R., Government Budgeting and Accounting Reform in Italy, in: Chan J. \& Xiaoyue C. (editors), Models of Public Budgeting and Accounting Reform, OECD Journal on Budgeting, Volume 2, Supplement 1, Paris.

Doran, G. T. (1981). There's a S.M.A.R.T. way to write management's goals and objectives. Management Review, Volume 70, Issue 11 (AMA FORUM), pp. 35-36

Flamholtz E. (1996). Effective Management Control: Theory and Practice, Kluwer, Norwell, Mass.

Hofstede G. (1978). The Poverty of Management Control Philosophy, The Academy of Management Review, 3,3 , p. $450-461$. 
Iyer, D (2011). Tying Performance Management to Service Delivery: Public Sector Reform In Malaysia, 20092011. Innovations for Successful Societies, Princeton University, http://www.princeton.edu/successfulsocieties. Accessed at on 9/12/124.

Malaysian Administrative Modernisation and Planning Unit (MAMPU) (2010). Together we transform. Putrajaya: MAMPU.

Merchant K. (1982). The Control Function of Management, Sloan Management Review, 23, 4, 43-55.

Ministry of Economy and Finance (2013). Economic and Financial Document, http://ec.europa.eu/europe2020/pdf/nd/sp2013 italy en.pdf

Mussari R. (2005). Public Sector Financial Management Reform in Italy, in: Guthrie J. - Humphrey C. - Olson O. (Eds.), International Public Financial Management Reform, Information Age, p. 139-168.

OECD, 2010. Modernising the Public Administration: A study on Italy, Public Governance Committee Meeting at the Ministerial level, Venice, 15-16 November

OECD, 2013. OECD Integrity Review of Italy. Reinforcing Public Sector Integrity, Restoring Trust of Sustainable Growth. OECD Public Governance Reviews, OECD Publishing.

O'Flynn, J. (2007). From new public management to public value: Paradigmatic change and managerial implications. The Australian Journal of Public Administration, Vol. 66, No. 3, pp. 353-366. http://wiki.douglasbastien.com/images/1/1d/From_New_Public_Management_to_Public_Value.pdf (accessed on 5 April 2014)

Ongaro, E., \& Valotti, G. (2008). Public management reform in Italy: Explaining the implementation gap. International Journal of Public Sector Management, 21, 2, p. 174-204.

Pollitt, C. (2006). Performance management in practice: A comparative study of executive agencies. Journal of Public Administration Research and Theory, 16(1), 25-44.

Siddiquee, N.A, (2010). Managing for results: lessons from public management reform in Malaysia, International Journal of Public Sector Management, Vol. 23 Iss: 1, pp.38 - 53.

World Bank (2012). World Bank Approach to Public Sector Management, 2011-2020. Washington D.C.: World Bank. At http://siteresources.worldbank.org/EXTPUBLICSECTORANDGOVERNANCE/Resources/286304-

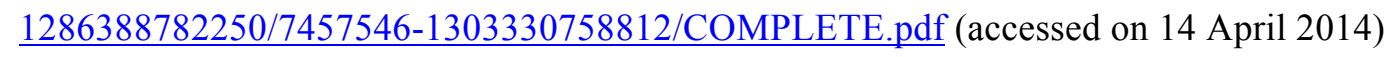

Xavier, J.A. (1996a). Budgetary Management and Control at the Malaysian Central Budget Process Principles and Practice. Journal on Financial Accountability and Management (UK), November 1996.

Xavier, J.A. (1996b). Budget Reform - The Malaysian Experience. Journal of Public Administration and Development (UK), Vol.16 (5), December, 1996.

Xavier, J.A. (2009). Establishing Key Performance Indicators for the Top Echelons of the Public Service. Excellence Journal Vol. 1(1). Putra Jaya: Malaysian Administrative Modernisation and Planning Unit (MAMPU). [Reprinted in Commonwealth Innovations, a Commonwealth Association of Public Administration and Management (CAPAM) Quarterly Publication. March 2010, Vol.16 No. 1.] 
Carmine Bianchi is a professor of business and public management in the Department of European \& Management Studies at the University of Palermo, Italy. He specializes in performance management and improvement, focusing primarily on the design and implementation of system dynamics-based, balanced scorecards. His most recent book is Modelli di System Dynamics per il Miglioramento della Performance Aziendale (IPSOA, 2009). He also has published in numerous academic and professional international journals. He can be reached at bianchi.carmine@gmail.com

John Antony Xavier is a professor of business and public management in the Graduate School of Business at the Universiti Kebangsaan Malaysia. He specializes in strategic management and performance management focusing primarily in performance agreements and scorecards. He has written a book on performance budgeting titled "Budgeting for Performance" (2002) published by the National Institute of Public Administration, Malaysia. He also has published in many international and local academic and professional journals. He can be reached at john@ukm.edu.my.

\footnotetext{
${ }^{\mathrm{i}}$ As core activities of internal control, the legislator emphasized the following: "benchmarking costs and yields, monitoring the achievement of objectives and the proper and efficient allocation of public resources, and the evaluation over the fairness and value of administration".

ii To this end, it requires that each year - within April 10th - the Ministry of Economy and Finance (MEF) submits to the Parliament an "Economic and Financial" document (DEF). This is a key step of the planning cycle. Referred to this document, an updating report must be also submitted each year to the Parliament by the MEF, within September 20th. Within October 15th, each year, the Government must then submit to the Parliament a "stability law proposal", as well as a law proposal for the approval of the State's financial plan. The "stability law" outlines public finance policies adopted for the next three years by the Italian public sector (not only at State level).

iii Disputes between political parties also have hindered progress in the area of system development and cultural change, and this has been exacerbated by the scarcity of public resources, due to the economic crisis and by the rigidity of current expenditures.

${ }^{i v}$ e.g.: data gathering and processing, reporting results, calculating variances, respecting deadlines.

${ }^{v}$ e.g., through performance data publication, benchmarking projects, user satisfaction surveys.

${ }^{\mathrm{vi}}$ Treasury Circular No. 5: Federal Budget Estimates, 1969. (Kuala Lumpur: Budget Division, Treasury).

vii Treasury Circular No. 11: Preparation of the 1990 Expenditure Proposals under the Modified Budgeting System (Kuala Lumpur: Budget Division, Treasury).

${ }^{\text {viii }}$ Performance reporting is carried out yearly through the exception report. The exception report requires an agency to submit - by February of the following year - a report on all performance that are inconsistent with the targets set - underor over-achievement - reasons for the inconsistent performance and the action to be taken to remedy such performance to prevent its recurrence.

${ }^{1 x}$ Prime Minister's Department (1992). Development Administration Circular No. 3/92: Guidelines on Micro Accounting System (Kuala Lumpur: MAMPU).

${ }^{x}$ Prime Minister's Department (1991). Development Administration Circular No. 6/91: Guidelines on Productivity Improvement in the Public Sector (Kuala Lumpur: MAMPU).

${ }^{x i}$ Prime Minister's Department (1992). Development Administration Circular No. 1/92: Guidelines on Total Quality Management for the Public Service (Kuala Lumpur: MAMPU).

${ }^{x i i}$ Prime Minister's Department (1993). Development Administration Circular No. 3/93: Guidelines on Clients' Charter (Kuala Lumpur: MAMPU).

${ }^{x i i i}$ Prime Minister's Department (1996). Development Administration Circular No. 2/96: Guidelines on MS ISO 9000 (Kuala Lumpur: MAMPU).

${ }^{\text {xiv }}$ Prime Minister's Department (1999). Development Administration Circular No. 1/99: Guidelines on Benchmarking (Kuala Lumpur: MAMPU).

${ }^{x v}$ Prime Minister's Department (2005). Development Administration Circular No. 2/05: Guidelines on Establishing Key Performance Indicators (KPIs) and Implementing Performance Measurement in Government Agencies (Putrajaya: MAMPU).
} 